\title{
Gender Mainstreaming vs Positive Action
}

\section{An Ongoing Conflict in EU Gender Equality Policy}

\author{
Maria Stratigaki \\ UNIVERSITY OF PANTEION
}

\begin{abstract}
This article examines the development of a gender mainstreaming strategy in the EU by illustrating how this strategy was shaped by other than gender equality policy goals. Gender mainstreaming was originally launched in 1996 to promote gender equality in all EU policies, in the context of international and European mobilization on women's issues. It was aimed to transform mainstream policies by introducing a gender equality perspective. However, it has been largely used as an alibi for neutralizing positive action. The successful implementation of positive action in political decision-making had challenged the gender distribution of political power over policy institutions and technical, human and financial resources. This led to policy softening and institutional weakening due to counteracting by the EU political and administrative hierarchies. The argument is based on text analyses of relevant Community acts and on direct observations of the policy process, based on personal working experiences in the European Commission.
\end{abstract}

KEY WORDS European Commission $\bullet$ gender equality policies $\bullet$ gender mainstreaming $\bullet$ positive action $\bullet$ women in political decision-making

\section{INTRODUCTION}

The article aims to contribute to the debate about the development of EU gender mainstreaming (GM) strategies by examining the context of its emergence in the mid-1990s. It is argued that the launch and rapid expansion of GM in the EU were largely shaped by the outcome of the conflict between two different policy frames of GM. One frame concerns its transformative role in public policies, complementing and reinforcing positive 
action and equality legislation. This frame was promoted as the central element of an EU hegemonic rhetoric at the World Conference on Women in 1995 and backed up by feminist theorists, women's organizations and institutions. The second frame presents GM as an alternative gender equality tool, which would gradually make positive action in favour of women redundant and which could be used to serve other policy goals. This frame was promoted by a number of key EU policy-makers and political forces within the EU who did not support the goal of de facto gender equality. The article shows that the policy outcome of the conflict, in the short term, was harmful to positive action in most EU policy areas, while in the long term it proved helpful in policy areas where gender equality coincided with other EU priorities, such as economic priorities of the European Employment Strategy or in policy areas that fell under the responsibility of feminist commissioners.

More precisely, the article seeks to explain how positive action was sidelined after the launch of gender mainstreaming as a result of the specific way GM was used by the opponents of gender equality to damage the dynamic created by the successful enlargement of the scope of gender equality in the Third Community Action Programme (1991-5) and the expansion of women's constituency in EU politics enhanced by the integration of Sweden and Finland.

The conflicts between the two policy frames are manifested in both implicit and explicit ways throughout the policy cycle. Shifts in policy frames occur in rhetoric, activities, instruments and mechanisms resulting in different policy outcomes. Examining the rhetoric and administrative changes that accompanied the development of the EU gender mainstreaming strategy reveals some of the explicit and implicit obstacles that confronted gender equality policies in the unique environment of European policy-making. These include the institutional context of the powerful and deeply hierarchical European Commission, where top-level administration and technocratic staff can play a decisive role.

This article is based on analysis of seminal policy documents, like the 1996 Commission Communication, the 1997 European Parliament Resolution and the 1998 Commission progress report on GM. By reflecting implicit and subtle shifts in policy frames and discourse, these texts reveal conflicts and compromises between different political interests, institutions and policy actors. The texts are placed in the context of changing policy environments, policy objectives and institutional structures as I have experienced them during my involvement in the planning and implementation of GM strategies in the Commission. ${ }^{1}$ In this context, I highlight the role of individual key players, politicians and civil servants in specific political and administrative decisions. I also assess immediate negative impacts on positive action and discuss the new opportunities that were opened in some EU policy areas. 


\section{MYTHS AND REALITIES ABOUT GENDER MAINSTREAMING}

Both 'gender' and 'mainstreaming' are conceptual terms that have evoked more confusion, misunderstanding and questions than any other terms used in EU equality policies. Until 1996, there was no clear definition in Community documents for the term 'gender mainstreaming'. The range of interpreted meanings included 'specific actions targeted to women in non-equality policies' and 'upgrading equality policy to a mainstream policy'. The approach to GM adopted in this study is based on the widely accepted definition of the Group of Specialists of the Council of Europe, which states that: 'GM is the (re)organisation, improvement, development and evaluation of policy processes, so that a gender equality perspective is incorporated in all policies, at all levels and at all stages, by the actors normally involved in policy-making' (Council of Europe, 1998: 15). A similar definition that stresses the importance of the 'transformation' of policies is given by Rees (1998: 40), who considers 'mainstreaming equality' one of the three major tools of sex equality policies, together with equal treatment legislation and positive action in favour of women.

Gender mainstreaming is the equality policy strategy that has been most critically assessed by feminists and women's organizations, who have pointed to the risks if the conditions for its success are not met and to the increasing evidence of significant weaknesses in its implementation. Research has been conducted on its emergence, its criteria for success and its transposition from one context to another (supranational to national) and from one administrative level to another (national to local). The multiple character of GM was highlighted by Vogel-Polsky and Beauchesne (2001), who added to the already long list of prerequisites, vast knowledge of the mechanisms of segregation and gender relations, as well as the capacity to analyse social contracts and policies. One of the most serious risks here is the gradual substitution of equal treatment guarantees. GM does not rely on law enforcement mechanisms but involves long-term transformation of public policies (Liebert, 2002; Pollack and Hafner-Burton, 2000). By emphasizing the danger of weakening gender equality policies altogether - a result of GM implementation Verloo (2001) argues that given gender power relations, GM becomes a political process in itself. Woodward (2003) too argues that in settings where political groups hope to reverse the progress of equality, GM is employed in questionable ways by dismantling women's policy machinery and committing no resources in its place.

Gender mainstreaming in the EU gained a high political profile thanks to its influential role in member states' equality policies. Research on its implementation has shown that, taking advantage of the political opportunities provided by the EU Treaty and the UN Platform for Action, 
supranational networks facilitated the adoption of this new policy strategy and its revolutionary potential in a wide range of EU policy fields, thus upgrading the EU to one of the most progressive polities with respect to the promotion of gender equality (Pollack and Hafner-Burton, 2000). GM was also analysed as a principal (and potentially radical) instrument towards achieving gender equality and challenging the liberal concept of equal treatment that views public policies as neutral. However, it has been argued that it is difficult to implement GM effectively when embedded cultural values and policy frames remain unquestioned; it is therefore understandable that women's organizations remain committed to grounding gender equality in law (Mazey, 2000, 2002).

Further research has explored parameters of GM efficiency. It was rightly argued that the effective implementation of GM in the multilevel Euro-polity can be achieved only if it takes root at all levels of decisionmaking; its successful transfer to national and regional levels can be largely facilitated by knowledge-based inducements, like elite learning and new governance instruments developed in the EU (Liebert, 2002). A comparison between GM in the EU and Norway has highlighted the importance of women in politics both in numbers and influence. This is the only way to guarantee a persistent active political will that is necessary for confronting everyday administrative and institutional resistance (Havnør, 2000). Research on GM in EU Structural Funds revealed some important aspects of the barriers within the European Commission services and correctly suggested that the 'European Commission is stronger on policy formulation than on developing accompanying arguments, procedures and instruments for translating policy into practice.' It was further argued that middle management reluctance and rivalry between services about power made progress dependent on certain people in the right positions at the right moment (Braithwaite, 2000).

Almost all analyses of GM agree that it is a strategy that complements but does not replace previous gender-specific equality policies like equal treatment legislation and positive action. The Council of Europe report states clearly that specific gender equality policies (legislation, mechanisms, actions to address specific women's interests, research and training) are a necessary prerequisite for successful implementation of GM (Council of Europe, 1998: 21). However, in hostile gender equality policy environments (i.e. patriarchal structures of institutional organizations or the prevalence of policy objectives contrary to gender equality, etc.), GM may be conceived and applied as an alternative to positive action and used to downplay the final overall objective of gender equality. In these cases, the most important innovative element of GM - the broadening of the scope and relevance of gender equality to all policies in the effort to transform them - becomes its major weakness, namely its use as an excuse for the elimination of gender equality specific policies. Such a risk 
increases in policy environments where these specific policies have been efficiently implemented and have challenged unequal gender distribution of economic resources and threatened men's political power.

The ambivalent outcome of GM, though, deserves more attention and analysis, as it should not be considered accidental or temporary but rather inherent and structural. GM challenges the whole policy cycle by introducing a gendered perspective to all phases, not only in the policy delivery phase as positive action does; a controversial usage may be the payoff for a policy shift from 'equal opportunities for women and men' to a 'gender equality' approach. One may initially argue that a gendered perspective to all policies is a more radical approach than applying PA on the level of individuals and social groups. However, in practice, thorough GM application becomes an almost Sisyphean mission. Strategies and policy instruments (even those for gender equality) are shaped within multiple gender hierarchies and thus become the implicit vehicles of the reproduction of inequalities. Without simultaneously tackling the accumulated inequalities between the sexes and reinforcing genderspecific policies, GM effectiveness cannot be assured.

In current EU public policies and existing gender regimes in member states, enhancing the complementarity of the two tools not only reduces risks and distortions, but also contributes to their mutual reinforcement. GM enlarges the scope of gender equality policies and limits its compartmentalization in target groups, policy-making machinery and the allocation of financial and human resources. Parallel positive action increases women's visibility and fosters gender equality by being diluted in other policy objectives or hijacked by other policy priorities. Arguments in favour of positive action highlight the advantage of introducing clear and measurable targets for women. Arguments in favour of GM highlight the importance of challenging the supposedly gender-neutral public policies with the aim of transforming the basis of analysis, the hypotheses about the expected impact, as well as the processes of its measures design. Considering GM and positive action competitive and eventual alternatives negates the multidimensional and structural character of gender relations and ignores the dangers present in policy environments that maintain existing gendered hierarchies.

\section{FROM EQUAL OPPORTUNITIES TO GENDER MAINSTREAMING}

In the EU, GM was launched after almost 40 years of equal treatment and positive action policies in the labour market. First gender equality concerns were introduced in the form of legislation on equal pay and equal treatment between women and men in the light of Article 119 of the 
Treaty of Rome and the mobilization of the post-1968 labour and women's movement (Hoskyns, 1996). The first area of conflict between supporters and opponents of gender equality was about whether positive action should be included in the Equal Treatment Directive (76/207/EEC). Positive action was dropped during the final negotiations of the Directive, becoming instead the subject of a Council Recommendation (84/635/EEC), a soft EU act. In spite of their complementarity, as argued by feminists and gender experts, positive action was seen as contradicting equal treatment legislation. Positive action in employment, however, was promoted though actions supported by the medium-term programmes for equal opportunities for women; it was initiated in the first action programme (1982-5) (CEC, 1982) and consolidated in the second (1986-90) (CEC, 1986). ${ }^{2}$

Equal opportunities for women in the labour market were promoted through the specific funding of vocational training and employment schemes for women by the European Social Fund (ESF), since 1977 already a part of its general policy. Since 1988, 'equal opportunities between women and men' became a specific measure under Objective 3 of the EU Structural policy (Council Regulation 4255/88). ${ }^{3}$ In its annual report Employment in Europe, launched in 1989, the Commission admitted that women's employment was important for the analysis of the European labour market and introduced a women's chapter (CEC, 1989). It was a newly appointed female commissioner, Vasso Papandreou, ${ }^{4}$ who personally insisted on this. A year later, she was instrumental in launching the most important ESF instrument for gender equality, the Community Initiative NOW (New Opportunities for Women), which earmarked a specific budget for women's vocational training that facilitated their integration into the labour market, including childcare infrastructure.

In 1990, GM was introduced into EU documents as one of the 'innovative features' of the third action programme for equal opportunities for women and men (1991-5) (CEC, 1990: 3); the addition of 'men' in its title was also an innovative feature. Two variants of the definition were proposed in the programme: (1) 'to take into account an equal opportunities dimension and the particular problems encountered by women in all relevant policies' and (2) 'to integrate equality into the general mainstream policy'. Although the official definitions use 'gender' as a component of GM, they ignore the structural aspect of the term and limit the description of the problem to 'differences in opportunities' as a reason for women's particular problems. These definitions characterize the transitional period - wherein the contextual phase shifted from 'women's dimension' to 'gendered dimension' in the development of gender equality policies in the EU (Booth and Bennett, 2002). What is further reflected here is the phraseology used by the two national experts from 
Denmark and the UK (Jacobsen and Brittan, 1989), who prepared the first draft of the third action programme. Here the 'new' tool was named 'mainstreaming equal opportunities policy'. Labour market and vocational training were the policies of primary concern for GM, although 'all relevant policies' like educational and social policies were also mentioned.

The Equal Opportunities Unit, in charge of the implementation of the programme, tried to enhance GM by proposing a gender impact assessment of employment policies, similar to the already existing impact assessment on the small and medium enterprises. As a first step, the Unit proposed the adoption of a Commission Communication, which, prepared by an external gender equality expert (Jacqueline Laufer), argued for the necessity of GM in Community policies and programmes, especially in employment and labour market policies. The 1993 Danish presidency had strongly supported it as part of its proposal to the Commission to take action for mainstreaming employment concerns in all Community policies; increasing unemployment rates having started to unsettle policy-makers. ${ }^{5}$ GM in employment policies was also supported by the Council Resolution initiated by the Greek presidency, which extended the scope of equal opportunities to all European Structural Funds (Council Conclusion 94/C 231/01/22.6.1994). However, this support did not prevent the draft Communication failing to pass through a reluctant male hierarchy and be adopted as a formal Commission document. GM was, in 1993, seen as secondary to what had become the main focus for DGV hierarchy: to mainstream employment in Community policies. In the new 'employment-dominated' European agenda created by the Conclusions of the Copenhagen European Council, gender mainstreaming was paradoxically put aside as irrelevant and luxurious, despite the existing evidence and awareness of the negative economic impact of the low European female activity rate, especially when compared to that in the US.

\section{ENHANCING WOMEN'S CONSTITUENCY, THREATENING MEN'S POLITICAL POWER}

Not surprisingly, the Third Community Action Programme had more success outside the Commission. Strong alliances with women's constituencies, in the European Parliament (EP) and the European Women's Lobby (EWL), ${ }^{6}$ as well as with individual women politicians and gender experts, created a positive environment for gender equality around the programme and its operational mechanism, the Equal Opportunities Unit (Stratigaki, 2000). The personal commitment of Agnès Hubert, head of the Unit from 1992 to 1996, played a crucial role in consolidating this alliance, which eventually favoured focusing on other 
innovative features in the programme, namely increasing women in political decision-making. This policy goal has prevailed in EU gender equality policies through a wide range of policy instruments, including background studies, theoretical texts, electoral campaigns, collected statistics and visibility events (EC, 1997b; Hubert, 1998), as well as a Council Recommendation (Council, 1996). A group of gender experts from all member states coordinated action and developed the European argumentation on gender balance in politics and on gender parity. Further elaboration on the concept of 'parity democracy' allowed the move from a quantitative claim to a qualitative necessity associated with structural change (Hubert, 2001). The active political support by the commissioner, female MEPs and national ministers was crucial in opening a window of opportunity for positive action for women in politics. An immediate result of these activities, in particular on the European-wide campaign, was the increase of women in the EP from 19 percent to 27 percent (after the 1994 elections and the integration of Sweden and Finland in 1995) and among European commissioners from one to five (out of 20) in 1995.

One of the five women commissioners was the Swedish newcomer, Anita Gradin, ex-Minister of Gender Equality and President of the International Association of Socialist Women. Her personal commitment to gender equality justified her request to bring gender equality policy in her portfolio together with justice and home affairs, both issues being under the responsibility of the conservative Irish commissioner Pádraig Flynn since 1993. Eventually, the President of the Commission, Jacques Santer, chose to keep gender equality policy with the Irish commissioner, whose interest and degree of commitment to gender equality was later publicly challenged by the EP Committee on Women's Rights. ${ }^{7}$ The pressure and criticism exercised by the EP urged the president to, instead, extend responsibility for gender equality to more commissioners and form a Group of Commissioners for Equality under his chairship. The members of the group were two men, Pádraig Flynn, in charge of social affairs (including gender equality) and the Finn Erkii Liikanen, in charge of personnel policy, ${ }^{8}$ as well as two women, the German social democrat Monica Wulf-Mathies, in charge of regional policy, and Anita Gradin. Unlike other similar groups, ${ }^{9}$ this group was open to other commissioners and, once a year, to the presidents of three major bodies representing the women's constituency in the EU: the Advisory Committee composed of national equality machineries, the EP Committee on Women's Rights and the EWL. This status was achieved as a result of the increasing political importance of the issues and the dynamic involvement of political, social and civil actors with high visibility.

The buoyant environment for gender equality in 1995 was reinforced by the exciting stir created by the agenda of the UN Fourth World Conference in Beijing, which urged governments to 'promote an active and visible 
policy of mainstreaming a gendered perspective in all policies and programmes, so that, before decisions are taken, an analysis is made of the effects on women and men, respectively' (UN, 1996). The EU actively supported this objective and further consolidated the progress on equality in Europe far beyond its original intentions as set before the Beijing Conference by a Communication for this purpose (CEC, 1995a).${ }^{10}$ Shortly after the UN Conference, the Commission adopted two Communications, one on integrating gender issues in development cooperation (CEC, 1995b) and a second on the external dimension of human rights policy including women in its target groups (CEC, 1995c). All women commissioners committed themselves to developing GM in the policies of their respective Community competence. By the same token, the Council of Ministers also mobilized by adopting two Resolutions on equality issues beyond the labour market with respect to decision-making and image in the media (Council, 1995a, 1995b) under the dynamic presidencies of Simone Veil for France and Cristina Alberti for Spain.

However, in spite of this wide interest in gender equality, the overall political and administrative responsibility for the EU gender equality policy was still in the hands of Commissioner Flynn and his Directorate General Employment and Social Affairs (DGV). All bona fide political will had to be coordinated, translated into specific policies and consolidated in Community programmes by allocating human and financial resources and developing appropriate mechanisms and policy instruments. This task necessitated substantial administrative changes aimed at creating and reinforcing existing structures and policy machineries. Specific equality staff would, then, organize the provision of necessary technical and theoretical knowledge of gender analysis in respective policy areas by external experts and researchers.

What effectively happened in DGV went in the opposite direction, despite the equality-sensitive background of the newly appointed, socialist, Director General, Allan Larsson from Sweden. Changes were made that depoliticized GM implementation, underutilized existing human resources and reduced the use of external expertise on gender issues. More precisely, the Equal Opportunities Unit was marginalized with the removal from office of its head, Agnès Hubert, in April 1996, and the management of the action programme was externalized to a technical assistance office, managed by a consortium of companies with no prior experience or expertise in gender issues. ${ }^{11}$ In addition, seven out of the nine gender expert groups operating in different policy areas under the third action programme, including those on women in decision-making and positive action, were discontinued, despite the plea of the EP Committee on Women's Rights and the EWL. These administrative decisions, with their important political impact on gender equality perspectives, were taken after the appointment, in April 1995, of the 
French female Commission official Odile Quintin to the post of Director of Employment (in DGV), who was in charge of equality policy among others. One year later she moved to the post of Director of Social Dialogue (also in DGV) bringing with her the responsibility for the Equal Opportunities Unit. The full assignment of gender equality policy to her has contributed to its softening, as Odile Quintin was known in the Commission to be ambitious and able to reframe EU policies as requested by her political hierarchy. In this specific period, she was even more effective because there was a political coincidence with Commissioner Flynn, who had been renominated for his second term (1995-9) and had relied upon her experience and professional capacity for the shaping of EU social policies in accordance with his party politics.

\section{THE LAUNCH OF GM: EMPTY RHETORIC DESPITE SUPPORTIVE ENVIRONMENT}

The high political profile of GM in the EU had created high expectations among feminists both inside and outside European institutions. The Commission had to react positively to broad political agreement with respect to the new strategies, as was advertised in Beijing. Rightly, the Communication 'incorporating equal opportunities for women and men into all community policies and activities' adopted in February 1996 was considered a landmark policy document in the EU (CEC, 1996). The definition of GM in this document states 'mobilising all general policies and measures specifically for the purpose of achieving equality by actively and openly taking into account at the planning stage their possible effects on the respective situations of women and women (gender perspective)' (emphasis in the original). The Communication also includes a review of Community policies including employment, information, education and development cooperation.

The Communication stressed the importance of the EU policy on equal opportunities in different policy areas, but failed to address any major objective, instrument or strategy for implementing GM. In fact, the 1996 Communication was much weaker than the text of the Commission Communication issued before the UN Conference (CEC, 1995a). In the latter, women's participation in political decision-making is a principle and a strategic objective of Community action, as it is considered an important indicator of democracy (para. 28). It is also stated that until a parity democracy is reached, women's interests must be fully integrated in general policies (Conclusion). On the contrary, the 1996 Communication not only failed to add any substantial value but also avoided any reference to the crucial connection between GM and women's participation in decision-making. The text referred more to the importance of the 
involvement of as many actors as possible (with the exception of women as decision-makers) than to the core element of GM, the transformation of existing public policies. In the Communication, GM lost most of its strategic sense vis-a-vis gender equality as it became an abstract 'principle' used interchangeably with the 'principle of equality'.

More seriously perhaps, GM was presented as a single concept, with no accompanying analysis of gender, gender relations, gender impact assessments and other related concepts and instruments. Rather, mainstreaming came to be connected to some general concepts, such as the 'new partnership between women and men' and 'democracy', concepts generic enough to dilute equality instruments and arguments. The Communication did little to improve readers' understanding of why and how the Commission intended to implement a new policy instrument for equality between women and men. In the examples of equality in EU policies, no reference was made as to the aims, or the expected outcomes, of incorporating a gendered dimension. This section of the Communication could have been part of an ordinary report on equal opportunities as it only described positive actions in different policy areas. In the concluding section, an attempt was made to present an implementation strategy for the principle of mainstreaming in 10 sentences that propose mechanisms to monitor processes, indicators and procedures and 'when necessary, experts' reports'. No reference was made to a timetable or to the allocation of funds and human resources.

The drafting of the Communication was assigned by Odile Quintin to two male officials, one her adviser and the other in charge of the Group of Commissioners at the General Secretariat. Neither had any prior experience in dealing with gender equality and they were not exposed to inputs from the Equal Opportunities Unit, which had followed the work in the Council of Europe on GM and which could have provided expert knowledge. Inputs from the Unit or external equality experts were rejected by the director as adopting a 'women's ghetto' approach and thus not suitable for the new era of GM, which addressed all policies and all actors, not only equality-focused policies and feminists. This further excluded the Unit from internal discussions and negotiations before its adoption by the Commission and legitimized the position that GM could be designed and implemented by anyone, without recourse to specialists.

The weakness of the Communication both in terms of theory and implementation provoked immediate reactions in the EP Committee on Women's Rights and the EWL. In its pertinent resolution, the EP contributed considerably to the clarification of strategies and tools by adopting the majority of the elements stated in the Council of Europe document. In its report, it argued in favour of the following issues: an approach that combined GM and positive actions (para. 11), the definition of assessment criteria (para. 14), the identification of obstacles created by 
culture and rigid societal structures (para. 16), the development of gendersensitive indicators (para. 29), the importance of coordination structures and budget lines within the Commission (para. 39) and the introduction of a gendered perspective to legislation (para. 43) (EP, 1997). In its position, the EWL proposed the following definition: 'the full integration of the gender perspective into all policy areas by giving equal consideration to the values and needs of both sexes' and argued in favour of positive actions, of a special budget for mainstreaming and of completing mainstreaming with special measures to promote women in decisionmaking positions (EWL, 1996).

\section{POSITIVE ACTION AND GENDER EQUALITY SPECIFIC POLICIES UNDER RISK}

The lack of involvement of the Equal Opportunities Unit in the Communication's formulation and its adoption, in spite of the critical reactions of the EP, the EWL and gender experts, indicates that its very weak approach to the mainstreaming of gender equality was not accidental. What happened can only be explained by the existence of deliberate opposition to the full effects of GM, which challenged other interests in the Commission. The threat of rebalancing the existing gender distribution of political power in the EU institutions appears to be a decisive facilitator in this direction. The Kalanke Judgement (European Court of Justice Case C-450/93) in 1995, which challenged positive action, provided further backing for this weak approach to GM, in spite of the clear reaction of women's constituencies.

Evidence of the use of GM to eliminate positive action can be found in EU labour market policy texts. The annual Commission report Employment in Europe included a separate chapter on women's employment from 1989 until 1993 and applied an ex-post gender proofing of all chapters in 1994. By 1995 both these efforts to introduce equality had been discontinued, with the excuse of applying GM in the drafting of the report. The synoptic table of all measures adopted by member states to reduce unemployment provides further evidence. The Tableau de Bord, in its 1995 edition, included a separate section on measures aimed at equality for women and men in the labour market (EC, 1996: 199), whereas, in the 1996 edition, equality measures were integrated in the chapter on measures addressed to social groups hit by unemployment. This restricted the scope of equality measures from those covering the labour market as a whole to those covering unemployed women, a fact that was justified in the forwarding address on the basis of GM (EC, 1997a). The trend to prioritize socially excluded groups instead of women as a whole was exemplified in the case of Community Initiative EQUAL, which aimed at combating 
discrimination in the labour market. EQUAL replaced programmes targeting women in general (NOW and EMPLOYMENT-NOW). All of EQUAL's projects were invited to mainstream gender equality, while specific funds were targeted only at socially excluded women, namely single parents or parental leave users.

In the field of education, a ring-fenced budget was allocated to projects aimed at equality between women and men and gender sensitization in the field of education, which addressed gender stereotypes, school materials and the promotion of non-typical educational choices for girls and boys. This budget was managed in close association with the Equal Opportunities Unit, ensuring a global coherence of the policy. In 1996, this specific budget was discontinued with the argument that the new programme for higher education, SOCRATES, 12 had mainstreamed gender equality (CEC, 1998: 9).

In the same vein, all forms of gender equality mechanisms armed with distinctive human and financial resources were put in question. The EP Committee on Women's Rights was challenged as to its necessity, role and added value in the EU policy agenda. It survived after the restructuring of the EP committees in 1998, thanks to strong advocacy exerted by its Green Finnish president, Heidi Hautala, actively supported by most of its Socialist Members. However, the new Committee was renamed 'Committee on Women's Rights and Equal Opportunities', signifying the shift from focusing on women to including men in its scope. ${ }^{13}$

The fourth action programme for equal opportunities (1996-2000) survived as it adopted GM as its main objective and became the vehicle for its promotion (CEC, 1995d). Consequently, there was a clear shift in how and to whom the action programme's limited available funding was allocated. Till 1995, equality projects funded by the action programmes were primarily small, transnational projects initiated and implemented by women's organizations throughout the EU, covering the whole range of the programme objectives. From 1996, funding was addressed to largescale projects proposed and implemented by non-specific organizations such as social partners and local authorities. This deprived EU gender equality policy from the energy and enthusiasm of feminists and of an important and useful input by the highly mobilized women's civil society.

\section{NEW OPPORTUNITIES BY INTRODUCING A ‘DUAL STRATEGY'}

Trying to identify and tackle weak spots in the GM application in line with the criticisms of the EP and the EWL, the staff of the Equal Opportunities Unit eventually settled for the 'dual strategy' or 'twin track' approach (combining GM and specific actions), as the only possible 
remedy that could rebalance the shift in equality policy frames. Only two years after the Commission Communication, the same Commission adopted the first progress report on the follow-up of the Communication (CEC, 1998). This time the report was prepared by the Unit and by the Norwegian national expert, Anne Havnør, whose contribution was crucial in the monitoring by a Commission inter-service group on this issue from 1996 to 1999. The report was clearly far more critical than the 1996 Communication in terms of gender equality, and recognized the importance of a 'dual strategy'. 'Programmes, positive action measures and budget lines/budgetary allocations specifically targeted to equal opportunities should complement the mainstreaming approach' (CEC, 1998: 7). A high level of commitment, awareness, gender expertise and monitoring and evaluation (gender impact assessment and gender proofing) were identified as conditions of success for GM. At the same time, a new, more comprehensive definition of the concept was introduced in the EU glossary on equality as follows: 'the systematic integration of the respective situations, priorities and needs of women and men in all policies and with a view to promoting equality between women and men and mobilising all general policies and measures specifically for the purpose of achieving equality by actively and openly taking into account, at the planning stage, their effects on the respective situations of women and men in implementation, monitoring and evaluation' (EC, 1998: 29).

A dual strategy approach was already partially reflected in the Treaty of Amsterdam, following a systematic campaigning and the multilevel action coordination by the EWL that maximized the opportunities offered by the 'window of reform' opened by the 1996 Intergovernmental Conference (Helfferich and Kolb, 2000). This resulted in Article 2, stating that equality between women and men is a Community task, and Article 3, stating, 'Community shall aim to eliminate inequalities, and to promote equality, between women and men'. Article 141.4 allowed 'specific advantages ... . for the underrepresented $\operatorname{sex}^{\prime}$ (EU, 1997). The scope of this positive development is, however, limited by the fact that these provisions do not provide strong legal bases, leaving the larger part of responsibility for their implementation upon political will and a favourable policy environment.

The dual strategy was launched and promoted as a remedy by feminist EU officials, whereas it was effectively implemented by feminist politicians. In particular, there were three women commissioners, who exploited contradictory policy frames by largely using Commission rhetoric and official documents, including the 1996 Communication, in legitimizing their equality policies. Three policy areas, two new to equality (EU research and technology policy, and home affairs and justice) and one old area (EU structural policy), fell under the political responsibility of socialist women commissioners, the French Edith 
Cresson, the Swedish Anita Gradin and the German Monica WulfMathies. They succeeded in mobilizing women's constituencies (including in the EP and the EWL) and built up a policy environment attuned to enhancing gender equality in the EU.

Edith Cresson initiated policies challenging the under representation of women in research and technology. Among her first decisions was to launch Marie Curie student scholarships, open to students of both sexes but with a name likely to encourage girls to apply. In 1999, a clear EU strategy and action plan on 'Women in Science' was launched, as part of EU research and technology policy. This recognized the need to promote research 'by, for and about women' and has become the best example in the EC of combining both positive action and GM measures (CEC, 1999).

Despite the opposing opinion of the Commission's legal service, Anita Gradin managed to establish the issue of the trafficking of women in the agenda of home affairs policies and, in 1997, launched the DAPHNE initiative, ${ }^{14}$ aiming at combating violence against women. Her action exemplified the potential of EU policy among women and a feminist constituency. Monica Wulf-Mathies was influential in introducing a GM strategy in the EU Structural Funds policy and allocated specific funds to tackling women's low participation in the labour market and the high female unemployment rate. The subsequent regulation of the European Structural Funds for the period 2000-6 (Council, 1999) integrated a dual track strategy, as well as a series of well-founded instruments and monitoring mechanisms. ${ }^{15}$

Further evidence of the influence of individual women politicians instigating specific action for gender equality, along with GM, is the case of the Framework Strategy for Gender Equality (2001-5) (EC, 2001). The Framework Strategy was adopted thanks to the personal commitment of Commissioner Anna Diamantopoulou (who replaced P. Flynn for the employment and social affairs portfolio in 2000) and Barbara Helfferich, member of her cabinet and formerly General Secretary of the European Women's Lobby. In the then current political and administrative environment of DGV, it was envisaged to discontinue the long tradition of midterm action programmes with the excuse of gender mainstreaming. The adoption of the Framework Strategy programme was a marked success in this difficult environment, and made clear progress in the EU discourse on gender equality by structuring the policy around five areas of gender equality active citizenship: economic, political, social, cultural and civil.

These positive developments of EU gender equality policy were built upon a favourable international environment in the late 1990s, but they were too dependent on the political will of individual women politicians. The transformative effect of GM on the respective policy processes and mechanisms was far too limited, and was lost with the departure of the women politicians and technocrats who had initiated and supported 
these policies. ${ }^{16}$ The persistence of equality priorities in the agenda seems to be easier when gender equality objectives coincide with other, stronger EU policy priorities, as it was demonstrated in the case of EU policies for work-family balance (Stratigaki, 2004); this gender equality concept was coopted by economic priorities and shifted in meaning and expected policy outcome. Cooptation by economic priorities seems to be the case also for women-targeted labour market measures and GM in the guidelines of the European Employment Strategy. These measures proved, eventually, insufficient to prevent the regression in some aspects of women's situation, as shown by the appearance of new gender inequalities in the form of women's proliferation in part-time and temporary jobs.

\section{CONCLUSION}

The article has explored the emergence of GM in the EU and analysed the steps both forwards and backwards for gender equality as an outcome of the underlying conflict between GM and positive action. It has pointed out the important role of institutional and administrative changes, as well as of women politicians, in enhancing gender equality policy, taking into consideration the patriarchal culture of European institutions and the mobilization of women's constituencies. It has demonstrated that the transformative effect of GM was minimal and its application has led to contradictory results. It opened important opportunities for specific policies in new policy areas, whereas in others it diluted positive action.

On the positive side, by implementing GM, the EU gender equality policy frame was extended beyond equal treatment legislation and positive actions; the neutrality of all policies at all levels was questioned and new directions for policy change were introduced. The potential of a more radical analysis of policies through a gendered perspective challenged the status quo in the EU policy system and invited strong resistance to understanding and endorsing the new equality strategy. Male-dominated decision-making bodies of the European Commission welcomed and constructed rhetoric on GM, which accommodated a current political environment in alignment with women's enthusiasm. However, they showed blatant reluctance in implementing this equality policy due to conflicting policy frames. One of the ways to disguise this reluctance was to insidiously assign GM the role of eroding positive action. This necessitated conceptual and perceptual shifts deliberately put forward in official texts.

Examination of EU official texts on GM, as presented in this article, exemplifies the way EU policy discourse may evolve rhetoric devoid of substance with regard to political commitment and concrete policy 
instruments and measures. The texts and the administrative and institutional changes observed reveal underlying policy interests and intentions by policy-makers; specific words are selected and specific technocratic decisions are taken. The analysis showed the role (and power) of the high and middle management of a bureaucratic structure, which drafted documents, selected words, manipulated meanings, delegated powers to individuals and shaped women's constituencies' expectations. Reading between the lines of the 1996 Communication suggests that it was conceived less to increase the speed of gender equality policies and more to hamper progress. It was also felt (and often internally argued) that the ambiguous and feeble rhetoric of the Communication risked setting back gender equality in the EU: (1) it incited arguments against positive action by stressing the concern of all actors for gender equality (a job for everybody $=a$ job of nobody); (2) it undermined radical elements of GM, such as the process of transformation of policies and the role of female decision-makers in implementing it; and (3) it halted the post-Beijing Conference dynamic and the momentum gathered following the enlargement to the North. ${ }^{17}$

Analysis of the barriers to implementing GM shows that the problem was not that it was newly established and needed a 'period of grace' for policy actors to assimilate it. Barriers are primarily erected because GM is infiltrated by feminist concerns suggesting fundamental changes in ways of thinking and understanding society. GM can potentially challenge and transform gender-biased public policies. However, this policy goal interferes and clashes with other dominant policy frames of the EU based on hierarchical gender distribution of power. Conflicts between political powers, civil society interests and national identities across EU institutions over competencies and territories produce unexpected effects on certain policy areas. The article has shown that the concept of GM was formally fully endorsed by policy-makers, but its implementation was manipulated so that it served to counteract the emerging demand of women for binding positive action measures in decision-making bodies. Challenging the gender distribution of political power in EU institutions threatens personal interests and power positions of individual women and men who held specific posts in political and administrative hierarchies. As a result, conflicting interests marginalized some individual policy-makers and crucial prerequisites for GM like women's participation in decision-making, equality-focused policies and the allocation of funds and human resources remained on the margins of the scope of the policy agenda for gender equality.

Today, eight years after its launch, GM has so far failed to affect core policy areas or radically transform policy processes within the European institutions. Despite the existence of strong alliances among equalityfocused institutional mechanisms, bodies of women's constituencies and 
the abundance of EU official declarations and political commitments, central policy documents (annual programmes, budgets and legislation) remain largely outside the scope of the strategy. Gender equality is still kept outside the debate (and action) with regard to the core of EU policies, macroeconomic policies enforcing the European Monetary Union (Hoskyns, 2004) and the constitutional politics shaping European polity (Lombardo, 2005). Contrary to most expectations (and explicitly formulated demands), analysis of the Commission's White Paper on European governance and the work of the European Convention demonstrate the marginalization of feminist politics in these two cases (Shaw, 2002). The resistance to including gender equality among EU values in the Constitutional Treaty shows that difficulties persist. Feminist strategies may have to be revisited in terms of both modes of acting and modes of theorizing. They may have to rely more on the knowledge of how power, structures and individuals interact and how this frames EU policies and discourse. This knowledge may assist in preventing transformative GM from being a failed project. It may also assist in exploring the way that gender equality and European integration will intertwine more effectively in shaping identities and foster economic, political and social change, as argued by Hubert (1998).

\section{NOTES}

The author thanks Mary Braithwaite, Anne Havnør, Catherine Hoskyns, Agnès Hubert and the anonymous reviewers for their helpful comments and suggestions on former versions of the article.

1. I worked in the Equal Opportunities Unit of the European Commission from 1991 to 1999.

2. For a comparative analysis of EU action programmes on equal opportunities, see Hoskyns (2000).

3. For a detailed analysis of GM in the Structural Funds, see Braithwaite (2000).

4. Vasso Papandreou and Cristiane Scrivener were the first two women to be appointed to the post of European commissioner by Jacques Delors in 1988.

5. This concern eventually produced the EU White Paper Competitiveness, Growth and Employment (EC, 1994).

6. The EWL is a Europe-wide umbrella organization consisting of about 3000 women's organizations in all member states. The EU financially supports its operation.

7. Criticism by the EP Committee chaired by the Dutch Green MEP Nel van Dijk included reference to Flynn's public attack of Mary Robinson during her campaign for president in Ireland.

8. One can assume that under the combined influence of belonging to this group and coming from a gender-supportive national culture, Erkii Liikanen was particularly attentive to the promotion of women in the management posts in the Commission. 
9. Created in the wake of the one on Equal Opportunities, these other groups were formalized only in 1999 (President's Communication (SEC (1999) 1483).

10. A separate acknowledgement must be made to the Swedish delegation in Beijing, which actively influenced the EU position towards buttressing GM in EU policy.

11. Currently being sued by the Commission for mismanagement.

12. Launched by Decision 819/95/EC and amended by Decision 98/576/EC of the EP and the Council.

13. Under the influence of Anna Karamanou, who chaired the Committee from 2002 to 2004 and had once more to argue for keeping a Committee dedicated to women's rights, the name has been changed again. In the sixth legislature of the EP, it is 'the Committee for Women's Rights and Gender Equality'.

14. The DAPHNE initiative (1997-9) initiated funding of measures combating violence against children, young persons and women. The consequent DAPHNE programme (2000-3) was launched by Decision 293/2000 and DAPHNE II programme (2004-8) by Decision 803/2004/EC of the EP and the Council.

15. This had an extremely important positive impact on member states, in particular on those whose labour market policies depend to a great degree on EU funding such as Greece (EYSEKT, 2003).

16. Current rumours about discontinuation of specific gender equality action programmes with the excuse of the newly established European Gender Institute support this fear.

17. Swedish and Finnish women's organizations were too much 'newcomers' to prevent distortion of positive Nordic influence. Nordic women were facing EU policies with scepticism, which was fully understandable in the context of the Scandinavian social welfare system.

\section{REFERENCES}

Booth, Christine and Cinnamon Bennett (2002) 'Gender Mainstreaming in the European Union: Towards a New Conception and Practice of Equal Opportunities?', European Journal of Women's Studies 9(4): 430-46.

Braithwaite, Mary (2000) 'Mainstreaming Gender in the European Structural Funds', paper presented at Mainstreaming Gender in European Union Public Policy: A Workshop, University of Wisconsin-Madison, 14-15 October.

CEC (Commission of the European Communities) (1982) 'First Medium-Term Community Programme on Equal Opportunities for Women (1982-1985) COM (81)758', Bulletin of the European Communities Supplement 1/82.

CEC (1986) 'Second Medium-Term Community Programme on Equal Opportunities for Women (1986-1990)', Communication of 20/12/85. Bulletin of the European Communities Supplement 3/86.

CEC (1989) Employment in Europe, CE-55-89-366-EN-C. Luxembourg: OOPEC (Office for Official Publications of the European Communities).

CEC (1990) Equal Opportunities for Women and Men: The Third Medium-Term Community Action Programme 1991-1995. COM (90) 449, 6.11.1990.

CEC (1995a) Communication on a New Partnership between Women and Men: Equal Sharing and Participation - The European Community's Priorities for the Fourth UN World Conference on Women. COM (95) 221 final, 29.05.1995. 
CEC (1995b) Communication on Integrating Gender Issues in Development CoOperation. COM (95) 423 final.

CEC (1995c) Communication on the External Dimension of the EU's Human Rights Policy: From Rome to Maastricht and Beyond. COM (95) 567. 22.11.1995.

CEC (1995d) Proposal for a Council Decision on the Fourth Medium-Term Community Action Programme on Equal Opportunities for Women And Men (1996-2000). $\operatorname{COM}(95) 381$ final, 19.07.1995.

CEC (1996) Communication on Incorporating Equal Opportunities for Women and Men into all Community Policies and Activities. COM (96) 67 final, 21.2.96.

CEC (1998) Progress Report from the Commission on the Follow-Up of the Communication: Incorporating Equal Opportunities for Women and Men into all Community Policies and Activities. COM (98) 122 final, 4.3.1998.

CEC (1999) Communication Women and Science: Mobilising Women to Enrich European Research. COM (1999) 76.

Council of Europe (1998) Gender Mainstreaming: Conceptual Framework, Methodology and Presentation of Good Practice, EG-S-MS (98) 2. Strasbourg: Council of Europe.

Council (1995a) Council Resolution of 27.3.1995 on the Balanced Participation of Men and Women in Decision-Making. OJ C 168/4.7.95.

Council (1995b) Council Resolution of 5.10 .95 on the Image of Women and Men Portrayed in Advertising and the Media. OJ C 296/10.11.95.

Council (1996) Council Recommendation of 2.12.1996 on the Balanced Participation of Women and Men in the Decision-Making Process. (96/694/EC), OJ L 319/10.12.96.

Council (1999) Council Regulation 1260/21.6.1999 Laying Down General Provisions on the Structural Funds. OJ L161/1-42.

EC (European Commission) (1994) Growth, Competitiveness, Employment: The Challenges and Ways Forward into the 21st Century. White Paper. Luxembourg: OOPEC.

EC (1996) Tableau de Bord 1995. Follow-Up to the Conclusions of the Essen European Council on Employment. Luxembourg: OOPEC.

EC (1997a) Tableau de Bord 1996. Follow-Up to the Conclusions of the Essen European Council on Employment. Luxembourg: OOPEC.

EC (1997b) Women in Decision-Making: Panorama of Activities, 05 CE-05-575-EN-C. Luxembourg: OOPEC.

EC (1998) One Hundred Words for Equality. A Glossary of Terms on Equality between Women and Men, 05 CE-10-97-162-EN-C. Luxembourg: OOPEC.

EC (2001) Toward a Community Strategy on Gender Equality (2001-2005). Luxembourg: OOPEC.

EP (European Parliament) (1997) Report on the Commission Communication on Incorporating Equal Opportunities for Women and Men into All Community Policies and Activities. A4-0251/97.

EU (European Union) (1997) Treaty of Amsterdam Amending the Treaty on European Union. OJ C 340/10.11.97.

EWL (European Women's Lobby) (1996) Position on the Communication from the Commission: Incorporating Equal Opportunities for Women and Men into All Community Policies and Activities. Brussels: EWL.

EYSEKT (2003) Guide for the Implementation of Gender Equality Policies in the Design and Evaluation of the Actions of the Operational Programmes of the Third Community Support Framework. Athens: ESF Coordination and Monitoring Unit, Ministry for Labour and Solidarity (in Greek).

Havnør, Anne (2000) 'Partnership, Political Will and Agency-Gender Mainstreaming at the EC level and in the Central Administration of Norway', paper 
presented at Mainstreaming Gender in European Union Public Policy: A Workshop, University of Wisconsin-Madison, 14-15 October.

Helfferich, Barbara and Felix Kolb (2000) 'Multilevel Action Coordination in European Contentious Politics: The Case of the European Women's Lobby', working papers Reihe Soziale Bewegung und politischer Konflikt Nr. 4.

Hoskyns, Catherine (1996) Integrating Gender: Women, Law and Politics in the European Union. London: Verso.

Hoskyns, Catherine (2000) 'A Study of Four Action Programmes on Equal Opportunities', pp. 43-59 in Mariagrazia Rossilli (ed.) Gender Policies in the European Union. New York: Peter Lang.

Hoskyns, Catherine (2004) 'Mainstreaming Gender in the EU's Macroeconomic Policy: Institutional and Conceptual Issues', paper presented at the ECPR Conference, Bologna, 24-26 June.

Hubert, Agnès (1998) L'Europe et les femmes. Identités en mouvement. Rennes: Editions Apogée.

Hubert, Agnès (2001) 'From Equal Pay to Parity Democracy: The Rocky Ride of Women's Policy in the European Union', pp. 143-64 in Jytte Klausen and Charles S. Maier (eds) Has Liberalism Failed Women? Assuring Equal Representation in Europe and the United States. New York: Palgrave.

Jacobsen, Helle and Diana Brittan (1989) Equal Opportunities in the 1990s: Elements for a Draft Third Community Programme on Equal Opportunities. Brussels: DGV.

Liebert, Ulrike (2002) 'Europeanising Gender Mainstreaming: Constraints and Opportunities in the Multilevel Euro-Polity', Feminist Legal Studies 10: 241-56.

Lombardo, Emanuela (2005) 'The Participation of Civil Society in the European Constitution-Making Process', in Schonlau Justus et al. (eds) The Making of the European Constitution. Houndsmill: Macmillan.

Mazey, Sonia (2000) 'The Emergence of Gender Mainstreaming in the EU: Policy Succession in Hard Times', paper presented at Mainstreaming Gender in European Union Public Policy: A Workshop, University of WisconsinMadison, $14-15$ October.

Mazey, Sonia (2002) 'Gender Mainstreaming Strategies in the EU: Delivering on an Agenda?', Feminist Legal Studies 10: 227-40.

Pollack, A. Mark and Emilie Hafner-Burton (2000) 'Mainstreaming Gender in the European Union', Special Issue of Journal of European Public Policy 7(3): 432-56.

Rees, Teresa (1998) Mainstreaming Equality in the European Union: Education, Training and Labour Market Policies. London: Routledge.

Shaw, Jo (2002) 'The European Union and Gender Mainstreaming: Constitutionally Embedded or Comprehensively Marginalised?', Feminist Legal Studies 10: 213-26.

Stratigaki, Maria (2000) 'The European Union and the Equal Opportunities Process', pp. 26-48 in L. Hantrais (ed.) Gendered Policies in Europe: Reconciling Employment and Family Life. London: Macmillan.

Stratigaki, Maria (2004) 'The Cooptation of Gender Concepts in EU Policies: The Case of Reconciliation of Work and Family', Social Politics 11(1): 30-56.

UN (1996) Platform for Action and the Beijing Declaration. New York: UN Department of Public Information.

Verloo, Mieke (2001) Another Velvet Revolution? Gender Mainstreaming and the Politics of Implementation, working papers. Vienna: Institute for Human Sciences - IWM.

Vogel-Polsky, Eliane and Marie-Noëlle Beauchesne (2001) 'Introduction: la 
situation des femmes toujours inegalitaire', in E. Vogel-Polsky and M.N. Beauchesne (eds) Les Politiques sociales: ont-elles un sexe? Brussels: Editions Labor.

Woodward, Alison (2003) 'European Gender Mainstreaming: Promises and Pitfalls of Transformative Policy', Review of Policy Research 20(1): 65-88.

Maria Stratigaki is a lecturer on gender and social policy at the Department of Social Policy, Panteion University, Athens. She studied economics, sociology and gender studies in Athens, Paris and New York. From 1991 to 1999 she worked in the Equal Opportunities Unit of the European Commission and was director of the Greek Research Centre for Gender Equality from 1999 to 2002. She did research on women's work, gender and technology. Her current research focuses on the EU's policies for equal opportunities and gender equality. Address: Panteion University, Department of Social Policy, 136, Syggrou ave., GR-17671 Athens. [email: mstrati@panteion.gr] 